\title{
EPILOGUE
}

\section{TO THE READER}

We hope that having read this book, you now agree with what we said in the Preface, namely that

(1) You can become an inventor and can help others to develop their inventive ability.

(2) There are very many important human problems requiring inventive solutions.

(3) A study of the methods and principles of invention can be of positive help in developing creativeness and originality in oneself.

It will give us great satisfaction if, by writing this book and telling you of our own studies and methods, we become godparents or, even better, midwives to your inventions. 